\title{
The Epidemiology of Recurrent Violence and Its Relationship with Sentence Time in the Romanian Juvenile Prison System: A Two-Year Cohort Study
}

\section{Carmen-Valeria Baias}

Faculty of Integral Medicine, University EurAka, Therwil, Switzerland

Email: carmenbaias@yahoo.it

How to cite this paper: Baias, C.-V. (2022) The Epidemiology of Recurrent Violence and Its Relationship with Sentence Time in the Romanian Juvenile Prison System: A Two-Year Cohort Study. Open Journal of Epidemiology, 12, 12-30.

https://doi.org/10.4236/ojepi.2022.121002

Received: December 19, 2021

Accepted: January 21, 2022

Published: January 24, 2022

Copyright () 2022 by author(s) and Scientific Research Publishing Inc. This work is licensed under the Creative Commons Attribution International License (CC BY 4.0).

http://creativecommons.org/licenses/by/4.0/

\begin{abstract}
Background: Research suggests that a small number of persistent violent offenders are responsible for a majority of prison violence and tend to behave violently to a disproportionate amount. However, literature on patterns of violence in juvenile prisoners is limited. Method: In order to explore how subjects engage in violence while incarcerated in the juvenile prison system, the authors will examine both proximal and distal predictors of violent behavior among juveniles in custody. This study adds to the current empirical research by longitudinally examining dynamic risk factors of recurrent violent behavior across a population of juvenile prisoners (Mage $=16.21 ; 94.8 \%$ male) in custody in the Romanian juvenile justice system, starting from their entry date until the end of the follow-up period ( $\mathrm{Me}=2$ years). Results: Results from a series of repeated aggressive events survival analyses show evidence of a long-term deleterious association between pre-incarceration risk factors and poor developmental trajectory associated with violence. Adherence to destructive conduct in prison was consistently influenced by low ability to cope with the prison environment, although education level and family factors also mattered. Implications for prison professionals and forensic practitioners are presented. Conclusion: Recurring aggressive behavior is frequent for individuals who experience complex adverse experiences during childhood, suggesting that screening youths upon their admission into juvenile justice settings should include an assessment of their basic self-regulation needs. A greater focus on longitudinal studies may help improve the screening process and also follow the progress of each juvenile to warrant the efficacy of preventive programs in self-harm, according to their emerging needs.
\end{abstract}




\section{Keywords}

Violence, Risk-Assessment, Repeated Events Analysis, Juveniles, Prison System

\section{Introduction}

Determining the etiology of interpersonal prison violence is crucial, i.e., understanding whether a high incidence of aggression is caused by the prison environment or whether inmates adapt their conduct according to their pre-incarceration repertoire of values and mentalities. Aggressive behavior displays a higher prevalence in prisons than in the general population, with a rate of prison violence as low as $8 \%$ and as high as $88 \%$, varying based on definitions and methodologies used across studies [1]. Research demonstrates that a small number of persistent violent offenders are responsible for a majority of prison violence, as they tend to behave violently to a disproportionate degree [2]. Across behavioral, affective, and cognitive theories, current evidence suggests that people who display aggression towards others reported a reduction in their distress levels or negative emotions and also boost their self-esteem. Why people use violent behavior as a strategy to control their emotions remains still unclear [3] [4] [5]. Research in the neuropsychology of aggression separates violence into two bimodal dimensions, i.e., affective/reactive and instrumental/ premeditated violence [6] [7] [8]. Affective/reactive interpersonal violence is committed with "hot-blood"; the offender reacts impulsively and instinctively due to their emotions [9]. Such individuals cannot control their impulses even in less stressful situations [6] [8]. Their thinking is, to some extent, pathologically rigid, making them unable to cope adequately with new situations and uncertainty [7].

Similarly, a number of developmental risk factors such as violence in the family, family dissociation, abuse, and neglect have been examined in studies in an effort to explain why juveniles behave aggressively [10] [11]. It has been demonstrated that adolescent prisoners internalize improper strategies to cope with stress resulting from interactions with their parents prior to incarceration and further consolidate their own deficits in behavior.

Nevertheless, when explaining prison violence, focusing solely on parenthood was harshly criticized by Arsenio and Gold [5]. They argue that when analyzing violence in adolescents, highly aggressive responses are often considered evidence of emotional dysregulation resulting from a deficient parent/child relationship and poor problem-solving skills, with no distinction between the two. This raises further questions as to what extent low levels of parent/child emotional reciprocity overlap with moral transgressions experienced in the harshness of prison life and how these dimensions can actually influence one's understanding of fairness and compassion versus dominance and violence in the correctional environment [5]. Consequently, research designed for prison violence 
showed that considering only the dangerousness of an offense is not effective in modelling violent misbehavior, since we need to consider a comprehensive scenario, including developmental factors and the harshness of prison life.

Other authors have instead suggested that the longer a prisoner remains in prison, the better the prisoner adapts to prison life [12]. Wheeler, suggested instead that a long time spent in prison could function as a school of crime that reinforces criminogenic culture, antisocial thinking and violence [13]. Even more concerning, Walters considers the amount of time spent in prison as a proxy of instrumental aggression and a major cause of interpersonal violence and criminal learning styles [14]. When comparing long term prisoners with novice inmates, Walters, reported that deviant socialization operates in changing both thinking styles and identity [15]. The authors compared the thinking styles and social identity in 55 novice inmates against 93 prison inmates with at least five years of confinement. The Psychological Inventory of Criminal Thinking Styles was administered twice a year at 6 months in both groups. Whereas the novice prisoners demonstrated an increasing trend in criminal identity and violent thinking, the scores of long term confined inmates remained stable across the period. In this way, confinement became a process during which inmates serving their first sentence assimilated both significant instrumental aggressive behavior and antisocial values and thinking styles [15].

Currently, there is little empirical evidence upon which to base firm conclusions about interpersonal violence in prisons, as the challenging nature of prison life is less considered in specialty studies and the investigation of the evolution of risk factors during a prisoner's sentence has been insignificant in quantitative research. Prison misbehavior is caused by multifactorial sources and their investigation is necessary for quantifying the risks of prison violence.

\subsection{The Current Study}

This study is designed to address these limitations by longitudinally investigating proximal and distal factors linked to interpersonal violence within the juvenile prison system. The study contributes to the growing literature on violent behavior in institutionalized juveniles by examining the dynamic relationships between risk factors and patterns of persistent interpersonal violence, following up with a sample of juveniles in custody in the Romanian prison system during their sentence time.

The present study aims to expand our knowledge in two key aspects.

First, this study investigates how violent misconduct unfolds over time while serving a sentence in the juvenile prison system. Thus far, little research has been conducted on the developing risks in prison even though the dynamic risk factors assessment, Chapman et al., displayed evidence that acting on these factors from admission to discharge could discontinue the pattern of violence [16].

Secondly, this research includes adolescent wards in custody in the Romanian 
juvenile prison system, a population that has never been studied in any previous longitudinal studies. We believe that by examining dynamic risks in adolescence, we can intervene with psychosocial professional help in order to change the course of misconduct in this developmental age and provide vital information for designing rehabilitation programs in this cultural context.

\subsection{Romanian Youth Justice Background}

The nature and extent of violence in prison raises important but often troubling questions as to why the prevalence of violent riots and victimization in the prison environment is higher than in a community setting, and what part imprisonment plays in this destructive behavior as "environmental coping" associated with incarceration.

Drastic reforms were required in the Central and Eastern European justice system after the major political upheaval of 1989. By 2011, the use of incarceration had dramatically declined, custodial sanctions were extremely rare, and juveniles typically did not serve a sentence in prison except for very serious offences. Today, the vast majority of juvenile offender justice in Europe is managed by the courts using diversionary measures-juveniles typically do not serve a sentence in prison except for very serious offences. In Romania (as in Croatia, the Czech Republic, Hungary, Latvia, and Slovenia), prison sentences for juveniles are replaced by community sanctions, and custodial sanctions are extremely rare in comparison to the adult justice system [17].

A comparative analysis of violence in prisons between 2010 and 2014 in Romania reveals a significant reduction in attacks against staff, but at the same time there was an upward trend in terms of self-aggression and/or aggression against other inmates. Moreover, these behaviors increased tenfold from 2010-2013, compared to 2005-2009. This phenomenon has contributed to a dramatic increase in per-prisoner health care costs incurred by the justice system [18].

The human costs of violence are even higher than the institutional costs, as violence is significantly associated with prison riots, the strongest predictor of homicide and victimization in offender populations. To date, almost all of the existing bodies of evidence on correlates for misbehavior in prison are cross-sectional, and there remains a paucity of evidence on the perpetuation or discontinuation of aggressive behavior over sentence time. Subjects can often have more than one violent event during their imprisonment time (i.e., follow-up period), and to ignore the later events squanders vital information. This also raises the question of whether the causal process differed in the earlier period of imprisonment and the subsequent period. Thus, in order to understand subject-to-subject variation over time, and the effect of imprisonment over time, we developed an analysis of recurrent events. The goal of the present study is to examine predictors of violent events after incarceration and to investigate how behavior changes over time while serving a sentence in the juvenile prison system. 


\section{Method}

\subsection{Study Design}

The study is set up to be a two-year longitudinal project. This cohort study includes both retrospective and prospective information that spans from the time a prisoner enters the system (which could be any time between January 2009 and September 2012), until the end of the study timeframe (December 2012). The National Administration of Penitentiaries collects information in its database for each individual on a daily basis, and all instances resulting in acts of aggression were recorded from the moment of the prisoner's arrival.

\subsection{Participants}

The participants in this study were 439 juvenile inmates in Romanian prisons for minors and rehabilitation institutes who served at any point in time from January 1, 2009 to December 31, 2012. More than $90 \%$ of the juvenile prison population was included in the study. During this timeframe, 693 occurrences of violence were observed in 234 juveniles, meaning that $53 \%$ had at least one occurrence of a violent event.

\subsection{Database and Ethics}

The Romanian Prison System Database was used to gather the information. Before beginning the study, the host organization, the National Administration of Penitentiaries, gave written authorization to utilize the data for the purpose of this study. The E.H.E. Europa Hochschule EurAka, Switzerland-where the author conducted the research from 2017 to 2020-provided ethical approval as well. In order to develop the study successfully, additional data security and storage procedures were devised.

The Romanian prison service maintains a database of daily incidents that result in prison violence. The time of the incident and the description of every violent episode are both included in this data. In addition, as shown by Baias et al., this administrative database contains rich information for each individual in the categories of demographics, socioeconomic variables, personal background, penal and criminogenic history, and psychological assessments [19].

\subsection{Factors Associated with Demographics and Pre-Incarceration}

Gender, ethnicity, age, educational status, employment status, residence prior to incarceration, family circumstances such as parental status (both parents in the household, single parent, parentless, adoption/institutionalization), violence within the family, and whether the father and/or mother were ever sentenced to prison are presented in Table 1.

\subsection{Measures of Mental Well-Being}

The "Symptom Checklist 90" was used to derive objective measurements of mental well-being for this study (SCL-90). These measurements have been 
proven to be robust to retesting effects in a range of settings [19] [20], are frequently used in medical literature [21], and are valuable indicators of psychological health [22].

Table 1. Characteristics of the adolescents in custody during the period 2011-2012.

\begin{tabular}{|c|c|c|c|c|}
\hline Variable & Category & Male (\%) & Female (\%) & Total (\%) \\
\hline \multirow{4}{*}{$\begin{array}{l}\text { Parenthood } \\
\text { status }\end{array}$} & Dual parent & $219(52.64 \%)$ & $13(56.52 \%)$ & $232(52.85 \%)$ \\
\hline & No dual parent & $131(31.49 \%)$ & $5(21.74 \%)$ & $136(30.98 \%)$ \\
\hline & Missing & $66(15.87 \%)$ & $5(21.74 \%)$ & $71(16.71 \%)$ \\
\hline & Total & $416(94.76 \%)$ & $23(5.24 \%)$ & 439 (100.00\%) \\
\hline \multirow{4}{*}{ Homelessness } & Yes & $60(14.42 \%)$ & $10(43.48 \%)$ & $70(15.45 \%)$ \\
\hline & No & $346(83.95 \%)$ & $11(47.83 \%)$ & $357(81.32 \%)$ \\
\hline & Missing & $10(2.40 \%)$ & $2(8.70 \%)$ & $12(2.73 \%)$ \\
\hline & Total & $416(94.76 \%)$ & $23(5.24 \%)$ & $439(100.00 \%)$ \\
\hline \multirow{4}{*}{$\begin{array}{l}\text { Violence in } \\
\text { Family }\end{array}$} & Yes & $97(23.32 \%)$ & $9(39.13 \%)$ & $106(24.15 \%)$ \\
\hline & No & $274(65.87 \%)$ & $12(52.17 \%)$ & $286(65.15 \%)$ \\
\hline & Missing & $45(10.82 \%)$ & $2(8.70 \%)$ & $47(10.71 \%)$ \\
\hline & Total & $416(94.76 \%)$ & $23(5.24 \%)$ & $439(100.00 \%)$ \\
\hline \multirow{4}{*}{$\begin{array}{l}\text { Substance } \\
\text { Abuse }\end{array}$} & Yes & $76(18.27 \%)$ & $6(26.09 \%)$ & $82(18.68 \%)$ \\
\hline & No & $311(74.76 \%)$ & $15(65.22 \%)$ & $326(74.26 \%)$ \\
\hline & Missing & $29(6.97 \%)$ & $2(8.70 \%)$ & $31(7.06 \%)$ \\
\hline & Total & $416(94.76 \%)$ & $23(5.24 \%)$ & $439(100.00 \%)$ \\
\hline \multirow{4}{*}{$\begin{array}{l}\text { Penal Rec. } \\
\text { Parents }\end{array}$} & Yes & $78(18.75 \%)$ & $3(13.04 \%)$ & $81(18.45 \%)$ \\
\hline & No & $321(77.16 \%)$ & $17(73.91 \%)$ & $338(76.99 \%)$ \\
\hline & Missing & $17(4.09 \%)$ & $3(13.04 \%)$ & $20(4.56 \%)$ \\
\hline & Total & $416(94.76 \%)$ & $23(5.24 \%)$ & $439(100.00 \%)$ \\
\hline \multirow{6}{*}{ Education } & Illiterate & $98(23.56 \%)$ & $6(26.09 \%)$ & $104(23.69 \%)$ \\
\hline & Elementary & $117(28.13 \%)$ & $5(21.74 \%)$ & $122(27.79 \%)$ \\
\hline & Middle School & $178(42.79 \%)$ & $10(43.48 \%)$ & $188(42.82 \%)$ \\
\hline & High School & $23(5.53 \%)$ & $2(8.70)$ & $25(5.69 \%)$ \\
\hline & Missing & $0(0.00 \%)$ & $0(0.00 \%)$ & $0(0.00 \%)$ \\
\hline & Total & $416(94.76 \%)$ & $23(5.24 \%)$ & $439(100.00 \%)$ \\
\hline \multirow{4}{*}{ Hostility } & Yes & $247(59.38 \%)$ & $15(65.22 \%)$ & $262(59.68 \%)$ \\
\hline & No & $162(38.94 \%)$ & $6(26.09 \%)$ & $168(38.27 \%)$ \\
\hline & Missing & $7(1.68 \%)$ & $2(8.70 \%)$ & $9(2.05 \%)$ \\
\hline & Total & $416(94.76 \%)$ & $23(5.24 \%)$ & $439(100.00 \%)$ \\
\hline \multirow{4}{*}{ Sensitivity } & Yes & $214(51.44 \%)$ & $13(56.52 \%)$ & $227(51.71 \%)$ \\
\hline & No & $193(46.39 \%)$ & $8(34.78 \%)$ & $201(45.79 \%)$ \\
\hline & Missing & $9(2.16 \%)$ & $2(8.70 \%)$ & $11(2.51 \%)$ \\
\hline & Total & $416(94.76 \%)$ & $23(5.24 \%)$ & $439(100.00 \%)$ \\
\hline
\end{tabular}




\section{Continued}

\begin{tabular}{ccccc}
\hline & Rehabilitation & $139(33.41 \%)$ & $16(69.57 \%)$ & $155(35.31 \%)$ \\
$\begin{array}{c}\text { Typology } \\
\text { of Prison }\end{array}$ & Prisons for Minors & $218(52.40 \%)$ & $1(4.35 \%)$ & $219(49.89 \%)$ \\
& Adult Prison & $59(14.18 \%)$ & $6(26.09 \%)$ & $65(14.81 \%)$ \\
& Missing & $0(0.00 \%)$ & $0(0.00 \%)$ & $0(0.00 \%)$ \\
\hline \multirow{2}{*}{$\begin{array}{c}\text { Retention } \\
\text { Regime }\end{array}$} & Open & $161(38.70 \%)$ & $16(69.57 \%)$ & $177(40.32 \%)$ \\
& Cemi open & $140(33.65 \%)$ & $3(13.04 \%)$ & $143(32.57 \%)$ \\
& Preventive & $79(18.99 \%)$ & $4(17.39 \%)$ & $83(18.21 \%)$ \\
& Missing & $0(0.00 \%)$ & $0(0.00 \%)$ & $0(0.00 \%)$ \\
& Total & $416(94.76 \%)$ & $23(5.24 \%)$ & $439(100.00 \%)$ \\
\hline
\end{tabular}

Note. The variable "Penal Rec. Parents" indicates a dichotomous variable including two categories "1"-A parent has been imprisoned previously. "0"-Parents without prior imprisonment experience.

Juveniles are required to complete the "Symptom Checklist 90" upon entering the penal system (SCL-90). The questionnaire's 90 items are graded on a 5-point Likert scale with nine separate subscales. The SCL-90 is used to assess the intensity of a symptom. It is not a personality test and is aimed to measure a psychological symptom at the time of the interview. Respondents were asked to rate the severity of a certain thought or feeling in the last seven days. Each item in the questionnaire is rated on a 5-point scale of distress, with 0 (none) being the lowest and 4 being the highest (extreme).

The interpersonal sensitivity and hostility symptoms accounted for 91 percent of those who completed the questionnaire (398 cases), while the remaining 30 cases were phobic anxiety, depression, general anxiety, somatization, paranoid ideation, and obsessive compulsion. As a result, the outcome reported below only contained the two key target symptoms: interpersonal sensitivity (IS) and hostility (HOS).

IS comprises nine items and is characterized by feelings of worthlessness, low self-esteem, or personal inadequacy in interpersonal interactions. Hostility is a dimension (HOS) that consists of six different components. The strongest symptoms of those who score highly in this dimension include items such as, "I'm usually treated unfairly" or "Everyone is against me." A high score implies that the individual should be viewed as being at risk of having disruptive behavior. This dimension reflects feelings and actions associated with a negative state of rage. It includes symptoms of irritability, anger, and resentment.

\subsection{Criminal History and Prison Factors}

Consistent with the prison factors relevant in the aforementioned literature, this study also investigates the influence on self-harm of the following variables: "Previous penal records," "Typology of prison institution" and "Regime of de- 
tention." In this analysis variables such as "Offence against property," "Physical damage against a victim" and criminal records (e.g., "relapse status," "conviction type," "convicted act," "length of the sentence") were included.

\subsection{Destructive Behaviors-Outcome}

Individuals' behavior was observed on a daily basis for each instance of aggression, commencing with the time of internment-time (0) - and ending at the time of exit from the research (censored time). This study extends the research to repeat event analyses in order to gain a better understanding of the motivational reasons underpinning destructive behaviors in juvenile prisoners. Thus, the dependent variable is elapsed time until the occurrence of a violent event.

Violent events may be displayed in any form of inmate-on-inmate violence [18]. An analysis of recurrent events was developed in order to understand subject-to-subject variation over time, and the effect of imprisonment time is examined. In longitudinal analysis there is a growing interest in studying events that occur repeatedly for the same individual, as prisoners in custody can often have repeated violent events. Furthermore, there are studies that demonstrate that a small number of persistent violent offenders are responsible for a majority of prison violence and tend to behave violently to a disproportionate amount [1].

\subsection{Analytical Procedure}

The "time to event" approach was utilized to look at how covariables (social, psychological, and institutional) affect the risk of violence during confinement. This technique admits varying numbers of people in the study at different points in time (unbalanced data), as well as different time intervals (varying schedules) [23]. This method enables participants to enter and depart the study at varying periods. For comparing groups utilizing censored data, sample size and power calculations were considered [23]. For each group comparison, sample size calculations were performed with $80 \%$ power at a significance level of alpha $=0.05$ and a two-year follow-up time.

There is a tendency in social sciences to apply the method of "time to first event" as the end of the analysis. However, subjects can have more than one violent event during their imprisonment (i.e., follow-up period), and to ignore later events squanders vital information. Usually, "time to first event" was used in analyses, even for events that occurred repeatedly. However, due to interdependence between event times within the same individual, it is not possible to apply the Cox Model to assess the impact of multiple factors for repeated relapses. Applying the Cox Model in this case and assuming independence between repeated events would be faulty. Reviewing the literature, we found an array of models that dealt with repeated occurrences (see discussion in Amorim et al.), yet there was no published research that used these models to study violence or misconduct in prison [24]. For our research we applied the Lawless and Nadeau regres- 
sion, which we find to have the same functions as the semiparametric Cox regression, due to its straightforward continuation for repeated occurrences [25]. This technique requires knowledge of the moment at which each event occurs and is based on the calculation of the cumulative mean of the events [25]. Occurrence rates were compared according to demographic variables and pre-incarceration factors, controlling for prison factors. We assessed the effects on the survival periods for predictors and explanatory variables associated with pre-incarceration experiences, controlling for prison factors.

Data analysis was performed using the package "survival", version 2.36-12 R Statistical System.

\section{Results}

\subsection{Key Findings}

Demographic Characteristics of the Juveniles Offenders in Custody

Table 1 summarizes the variables of interest for male and female adolescents serving a sentence in the Romanian Juvenile Prison System.

The first key finding from this research is that juveniles coming from disadvantaged backgrounds (i.e., children with one or both parents missing, abandoned children, institutionalized children, homeless children, impoverished children, etc.) are overrepresented in prison. More than $20 \%$ of the adolescents in our study were missing at least one parent at home; the rate of neglect was unusually high in males at $68 \%$, more than double the female rate.

The second finding for this research question was that inmates in this study had a very high risk of presenting various combinations of low self-control, low ability to cope with frustration and emotion dysregulation. More than $60 \%$ of inmates in the Romanian juvenile prison system presented a low ability to cope with frustration and conflict when screened at their entry into the prison. These factors were more prevalent in female prisoners. However, due to the scarcity of female inmates in the data (i.e., 23 female prisoners), sample size was insufficient to allow separate estimations by gender. Thus, male and female groups were joined into a single sample.

\subsection{Differences among Groups in Recurrent Violent Occurrences. The Recurrent Event Analysis}

A total of 439 individuals were observed during this study. During the follow-up, 693 occurrences were observed in 234 subjects, meaning that $53 \%$ had an occurrence of at least one violent event. Of these 234 subjects, 132 had at least two occurrences of violent events, meaning that $56 \%$ of those with violent events had multiple events. 82 subjects had at least three events; meaning $62 \%$ of those with at least two events had a third event. 57 subjects had at least four events $(70 \%$ of those with a third event had a fourth event). The maximum number of recurrent events in a single individual was 42 . The mean number of recurrences per inmate was 1.58 with a standard deviation of 3.16 , therefore the ratio between the 
variance and the mean was about 10:1.

The cumulative mean number of events for two years of serving a sentence in the Romanian Juvenile Prison System is 2, with 221 inmates still in the system after two years from the 439 at the inception of the study. An important finding from this research is that the trend of interpersonal violence increases with the cumulative mean number of aggressions per inmate at 2.77 events at the 3 -year mark, although it differs according to a range of risk factors. The cumulative mean function yields specific information on how the violence rates vary with time spent in prison. Hence, considering the times at which the aggressive events occurred, it was possible to accurately achieve a more specific assessment of the predictive factors on violence when serving a sentence. Variables such as "gender", "educational attainment lower than high-school", "detention regime", "interpersonal sensitivity" and "hostility" were associated with higher rates of violent occurrences in custody.

Table 2 shows the results relative to the cumulative number of events observed during the follow up to 6 months, 1 year and 2 years, respectively. For example, as Table 2 and Figure 1 show, a low level of educational attainment is associated with higher rates of violent occurrences in custody. While the cumulative means of violent events for the educational categories: "illiterate", "elementary school", and "middle school" outline a similar pattern, being enrolled in high school displays a different pattern, with a mean number of violent events that is much lower than the others. At 6 months, the "Illiterate", "Elementary School", and "Middle School" levels display a similar cumulative mean of violent events represented by $\mathrm{M}(\mathrm{t})$ with a $\mathrm{M}(\mathrm{t})=0.76, \mathrm{M}(\mathrm{t})=0.55, \mathrm{M}(\mathrm{t})=0.46$, respectively, while being enrolled in high school reduces the number of occurrences close to zero (i.e., $\mathrm{M}(\mathrm{t})=0.13$ ). A comparison of the results reveals that after 1 or 2 years of serving their sentence, a similar pattern for the "Illiterate", "Elementary", and "Middle School" categories emerges, outlining a higher number of recurrences $\mathrm{M}(\mathrm{t})=2.13$ while the "High School" level remains constant i.e., close to zero (i.e., $\mathrm{M}(\mathrm{t})=0.18$ ).

The results relative to the estimated cumulative mean from the proportional means regression for the analysis of recurrent violent event data are displayed in Table 3. Males showed a higher rate of violent events than females (about 2.2 times that recorded in females) and serving a sentence in a closed regime increases the number of violent events about 2 times on average compared with serving a sentence in a less restrictive regime. In addition, the estimated effect on violent recurrencies is higher for those characterized by a higher risk of hostility $(\mathrm{b}=0.34, \mathrm{p}<0.001)$, and those with a low capacity for interpersonal sensitivity $(b=-0.73, p<0.001)$. Furthermore, while gender resulted as significant for recursive violence in the univariate analysis, gender was not predictive for maladaptive behavior when accounting for prison factors and educational attainment. It is also interesting to note that in the multivariate regression analysis, the estimates of the covariate "regime of detention" indicate that serving a sentence in less restrictive detention regimes (e.g., open, semi-open) is associated with a 
good prognosis $(b=0.80, p<0.001)$, reducing the rate of violent recurrences by a factor of 0.48 , or $52 \%$. Similarly, holding other covariates constant, being enrolled in high-school contributes to reducing the rate of violent occurrences (b $=-2.00, \mathrm{p}<0.001)$ by a factor of 0.18 , or $81 \%$. The analysis was run by introducing significant variables from the univariate analysis into a stepwise regression. For each step, a variable was considered for elimination from the set of independent variables, based on the Akaike information criterion (AIC).

Table 2. The cumulative mean number of events $M(t)$ observed during follow-up by groups.

\begin{tabular}{|c|c|c|c|c|c|c|}
\hline & 180 Days & & 365 Days & & 730 Days & \\
\hline & $M(t)$ & $\mathrm{n}$ & $M(t)$ & $\mathrm{n}$ & $M(t)$ & $\mathrm{n}$ \\
\hline \multicolumn{7}{|l|}{ Gender } \\
\hline Female & 0.1 & 23 & 0.2 & 22 & 0.9 & 11 \\
\hline Male & 0.6 & 401 & 1.1 & 351 & 2.1 & 90 \\
\hline \multicolumn{7}{|l|}{ Hostility } \\
\hline Yes & 0.8 & 258 & 1.4 & 232 & 2.6 & 74 \\
\hline No & 0.3 & 161 & 0.5 & 138 & 0.8 & 27 \\
\hline \multicolumn{7}{|l|}{ Sensitivity } \\
\hline Yes & 0.3 & 218 & 0.6 & 184 & 1.0 & 47 \\
\hline No & 0.8 & 199 & 1.6 & 184 & 3.0 & 54 \\
\hline \multicolumn{7}{|l|}{ Regime } \\
\hline Open & 0.2 & 171 & 0.5 & 159 & 1.0 & 56 \\
\hline Semi-open & 0.6 & 143 & 1.2 & 130 & 1.8 & 19 \\
\hline Closed & 1.3 & 36 & 3.0 & 36 & 6.1 & 23 \\
\hline Preventive & 0.7 & 74 & 1.0 & 48 & 1.3 & 3 \\
\hline \multicolumn{7}{|l|}{ Education } \\
\hline Illiterate & 0.8 & 102 & 1.3 & 92 & 2.1 & 30 \\
\hline Elementary & 0.5 & 122 & 1.1 & 106 & 2.3 & 32 \\
\hline Middle School & 0.5 & 179 & 1.0 & 154 & 1.9 & 38 \\
\hline High School & 0.1 & 23 & 0.2 & 20 & 0.3 & 1 \\
\hline & $\mathrm{N}$ observations $=1180$ & $\mathrm{~N}$ ev & $=690$ & & & \\
\hline
\end{tabular}

Note. The estimate of the cumulative mean function $M(t)$ is the sum of the mean number of events observed up to time t. For example, 416 males and 23 females were recorded for follow-up. At day one from the start of follow-up, 1 event was observed in males, so that the mean number of events observed at time1 is $\mathrm{m}(1)=$ n.events/n.subjects $=1 / 416=$ 0.0024; at day two there were 416 male subjects and 3 violent events were observed in this group. Therefore, the cumulative mean number of events is $\mathrm{M}(2)=\mathrm{m}(1)+\mathrm{m}(2)=1 / 416$ $+3 / 416=0.012$. As far as the violent events in the Romanian Juvenile Justice System are concerned, the cumulative means of number of recurrences after 6 months, 1 year and 2 years are for males, respectively, $0.6,1.1,2.1$. On the other hand, the cumulative means of number of recurrences for females remain low during the follow-up at $0.1,0.2,0.9$, respectively, at 6 months, 1 year and 2 years. 
(a)
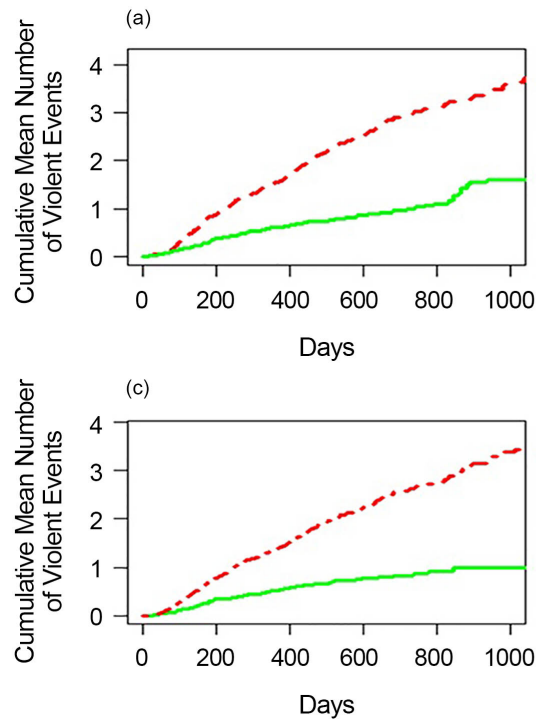

(b)
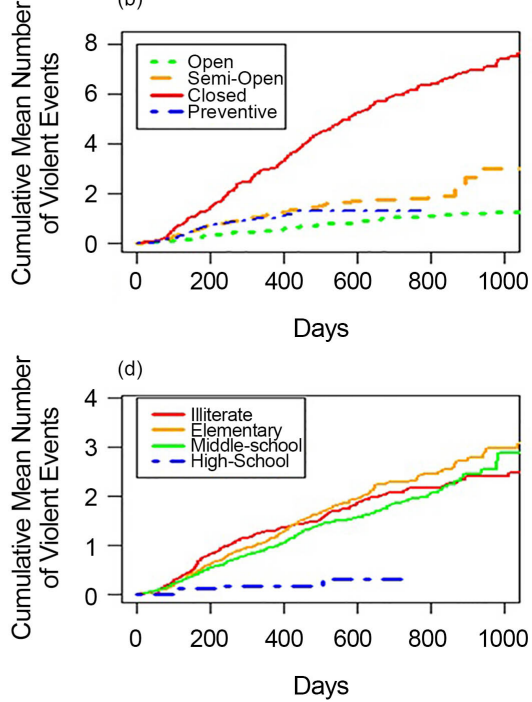

Figure 1. Estimated cumulative mean $M(t)$ describing inmates' violence (any type of violence) during their prison stay. Note. (a) shows the estimated cumulative mean of violent events $M(t)$, based on the ability to regulate emotion and sensitivity. The dotted line represents the predictive cumulative mean of any kind of violence for prisoners who were screened with low-ability. (b) shows the estimated cumulative mean of violent events, based on regime of detention. (c) shows the estimated cumulative mean of violent events by risk of low tolerance to frustration. The dotted line represents the predictive cumulative mean of any kind of violence for prisoners who were screened as having low-tolerance of frustration. (d) shows the estimated cumulative mean of violent events, based on level of education.

Table 3. Parameter estimates for the proportional means regression of recurrences for violent events.

\begin{tabular}{|c|c|c|c|c|c|c|}
\hline & \multirow{2}{*}{\multicolumn{3}{|c|}{ Proportional Means }} & \multirow{2}{*}{\multicolumn{3}{|c|}{$\begin{array}{c}\text { Proportional Means } \\
\text { Multivariate Analysis }\end{array}$}} \\
\hline & & & & & & \\
\hline & $\mathrm{b}$ & se & $\mathrm{z}$ & $\mathrm{b}$ & se & $\mathrm{z}$ \\
\hline $\begin{array}{c}\text { Gender } \\
\text { Female vs. Male }\end{array}$ & -0.795 & 0.347 & -2.292 & -0.562 & 0.361 & -1.559 \\
\hline $\begin{array}{l}\text { Hostility } \\
\text { Yes vs. No }\end{array}$ & 0.895 & 0.133 & 6.735 & 0.337 & 0.466 & 2.883 \\
\hline $\begin{array}{l}\text { Sensitivity } \\
\text { Yes vs. No }\end{array}$ & -0.831 & 0.125 & -6.653 & -0.729 & 0.098 & -5.675 \\
\hline $\begin{array}{l}\text { Detention Regime } \\
\text { Heavier vs. Open }\end{array}$ & 0.730 & 0.152 & 4.807 & 0.804 & 0.095 & 5.607 \\
\hline $\begin{array}{c}\text { Education } \\
\text { High-School vs. } \\
\text { Otherwise }\end{array}$ & -1.711 & 0.453 & -3.776 & -2.003 & 0.446 & -4.295 \\
\hline & $\mathrm{N}$ observations $=1118$ & $\mathrm{~N}$ eve & $s=690$ & & & \\
\hline
\end{tabular}

Note. The statistical quality of the model was assessed with the Akaike information criterion (AIC), which compares each model's goodness of fit. For each step, a variable was considered for elimination from the set of independent variables. A negative sign of the regression coefficients (b) means that the rate of violent events is lower, and thus the prognosis is better for subjects who have higher values of that variable. 
Results confirmed that lower levels of education, serving a sentence in a more restrictive regime, the inability to regulate sensitivity and emotion in response to those in close proximity, and hostility remained significantly associated with the number of violent recurrences, even when the joint effect of these variables was considered in a multivariate analysis. A negative sign of the regression coefficients (b) means that the cumulative mean of violent events is lower, and thus the prognosis is better for subjects who have higher absolute values of that variable.

\section{Discussion}

The goals of the present study were to examine predictors of violence after incarceration and to investigate how this behavior changes over time while serving a sentence in the juvenile prison system.

The analysis indicates that recurrent misbehavior in prison is highly associated with psychological vulnerabilities and a range of negative factors, both distal risk factors e.g., family factors, and more proximal ones, such as factors related to the prison regime. Four conditions shown to contribute towards violent behavior were: 1) Emotional dysregulation (i.e., interpersonal sensitivity dysregulation), 2) A low ability to cope with frustration and hostility, 3) Increasing levels of isolation in more restrictive detention regimes and, 4) Education level.

In this study, psychological well-being is inversely related to being in foster care, skipping school, being parentless, and being mistreated throughout childhood. Individuals who already experienced adverse experiences prior to incarceration had significantly worse than average emotional and psychological indicators at the moment of imprisonment. Furthermore, the experience of prison life in a restrictive detention regime (closed regime) incurs an additional substantial risk of violence. Variables such as "educational attainment lower than high-school", "detention regime", "interpersonal sensitivity", and "hostility" were associated with higher means of the occurrence of violence in custody.

\subsection{Ineffective Parenting and Prison Strains as Risks}

Ineffective parenting has been demonstrated to be the most important risk factor for the development of antisocial and violent conduct in children [10] [26]. Risk factors include hostile parenting, poor supervision [11] [27], and abandonment or neglect [28]. There are numerous studies showing that inadequate parenting leads to juvenile delinquency and violence. However, there is no information on those juveniles with unresponsive parents who do not go on to become delinquent or violent. Our study adds to the greater discussion, illustrating that when a variety of risk factors are considered-including ineffective parenting-a low-education level (illiteracy or at most elementary school level) along with "high hostility" and "low inter-sensitivity" traits, emerge as highly significant factors in those persistently violent while serving a sentence. These juveniles 
present impaired learning ability and a low ability to adapt and cope with their emotions during interpersonal interactions. Evidence-based programs that involve the family in an offender's rehabilitation suggest there is a degree of success in reducing subsequent offenses [29]. Nevertheless, in curtailing antisocial behavior and violence, the evidence is mixed and conflicting, mentioning that not all family-based programs are effective [26]. Furthermore, the specialty literature is limited by the fact that there is a lack of information on how people raised with inadequate parenting styles do not go on to become criminals. Our study demonstrates that there are persistent risk factors remaining influential on whether the offender will commit further violent activities during sentence in prison.

\subsection{Educational Attainment}

A great deal of previous research into inmate-on-inmate violence has focused on the associations between antisocial behavior and low educational attainment. In a literature review and meta-analysis performed in 2000 by Morgan and Lilienfeld, strong associations between antisocial behavior, intellectual function, and executive functions were consistently found across the studies [30]. It was demonstrated across the studies that antisocial groups consistently scored lower on intelligence tests compared with other groups. Our findings suggest that dropping out of school early and low-educational attainment impact problem-solving skills and the ability to process information. Consistent with the literature, our research found that inmates with a low-educational attainment also displayed a higher tendency of aggressive conduct during their sentence time. They also had more difficulty in effectively performing tasks that required self-control and inhibition. High scores of callous-unemotional characteristics [31] such as a lack of empathy, lack of guilt, or the predatory use of people for their own interests are acknowledged in studies as explanations for the source and severity of aggressive behaviors in samples of young offenders [31].

The role of hostility and self-control, in the relationship between low self-control, criminality, and violence has been emphasized by Gottfredson and Hirschi [32]. The authors integrated various aspects and concepts from the rational choice theory, routine theory, and biological and psychological theories in their general theory of crime, identifying parenting as fundamental for a child's antisocial mindset. Our findings support Gottfredson and Hirschi's general theory of crime, suggesting that chaotic household circumstances (i.e., homelessness), often coupled with neglect and abandonment, may indeed cause children to become less motivated to practice self-control. The uncertainty and unpredictability of these inadequate parenting practices cause children to discount the benefits of future rewards, since they feel unlikely that they will ever attain any. They act impulsively when confronted with more oppressive circumstances, and are less willing to delay gratification [32]. In conclusion, here, the disruptive behavior of adolescent prisoners leads back to a relational circle 
that seems to suggest a non-existent parental world, both in terms of support and control, where parents show complete disinterest in the developmental functions of their child. A framework seems to appear that outlines a serious decline of parental responsibility, which corresponds to a dual concept both as a reference model and as a barrier to overcome for the future.

\subsection{Limitations}

There are some limitations to the current study that are noteworthy of discussion. First, the data measuring violent misconduct in this database are somewhat limited as they were based on official information which was taken by officers, and probably devoid of context. This may happen due to the discretionary decision of the officers who report these negative occurrences, or subjects may be intimidated by the perpetrators who acted against them and are afraid of reporting it. However, given the longitudinal aspects of data, in which an inmate's behavior is followed over time from the moment of entry into prison, employing event history analyses for repeated aggressive occurrences, the findings remain robust.

Second, this study cannot identify adolescent males and females who were involved in misconduct as gang members; making it impossible to examine the implications of gang involvement in institutional misconduct. However, unexpectedly, this study demonstrated that those convicted of more serious criminal offenses were not significantly more likely to be involved in inmate-on-inmate violence when compared with the others.

\subsection{Implications of Findings for Practitioners and Future Directions for Research in Prison}

This study shows that adolescents who had a poor relationship with their parents prior to incarceration are more likely to present mental health issues, and those that present more mental health issues are more likely to commit acts of violence. The implications of these findings for rehabilitation policies are straightforward and despite this combination of considerable findings, several questions remain as follows:

Contrary to expectations, being classified as a high-risk offender in a more restrictive detention regime has no beneficial effect on instances of misconduct. It would be expected that a more restrictive regime would curtail misconduct, but that is not shown to be the case. These insights deserve further development in order to understand how prisoners could be incentivized or encouraged to change in this context.

In this study, individuals who display emotional dysregulation, low self-control, and low ability to cope with frustration are at higher risk of violent behavior. Nevertheless, it is difficult to estimate mental illness within the Romanian juvenile prison system, both due to the difficulties in finding a reliable diagnostic tool, and also due to inconsistent definitions that vary from one study 
to another. Therefore, it would be effective to consider the process of diverting those at risk of mental illness away from the criminal justice system in the first place.

Future studies need to examine risk factors that are supposed to be comorbid, both for mental illness and criminality, to further include specific needs and treatment for this particular vulnerable inmate population. In the Romanian juvenile prison system, the adolescent inmates have the opportunity to work, take part in education, cultural events, religious events, and educational and vocational training in small groups, albeit under surveillance in specific areas established within the prison. Moreover, these minors are rewarded by the Council Professors with permission to visit their family during the holidays, to school trips, or when going shopping when they make honest and balanced behaviour evident. However, while developing programs for treatment dedicated to inmates who present warning signs of mental illness, correctional policy makers must also deliver programs that meet the special needs for criminal rehabilitation and aim also to reduce criminal recidivism. The findings presented here suggest that a number of special programs need to focus on propensity towards antisocial behavior, independently of mental illnesses. The prison system needs to consider an integrated implementation of these programs rather than disparate or sequential programs.

\section{Conclusion}

Recurring aggressive behavior is frequent for individuals who experience complex adverse experiences during childhood (e.g., ineffective parenting or institutionalization), suggesting that screening youths upon their admission into juvenile justice settings should include an assessment of their basic self-regulation needs. The findings of this investigation complement those of earlier studies. These findings have significant implications for the understanding of how dropping out of school at a young age and low-educational attainment impact the development of information processing and problem solving. Hence, altogether, these variables indicate that various forms of neglect, or being subjected to abandonment in early childhood manifest later through maladaptive and violent antisocial behaviors-in the context of serving a prison sentence as well.

\section{Acknowledgements}

We particularly like to thank Professor Rocco Micciolo from the University of Trento for his invaluable consultation on the statistical analyses. This project would not be possible without the Management Services at the National Administration of Penitentiaries in Romania, who allowed access to develop it. We would particularly like to thank the managers, Dr. Ioana-Mihaela Morar, the Deputy Director, the Executive Director Prof. Ioan Bala, and the Director of Penitentiary Hospital, Mr. Dorin Muresan, for their practical support and understanding over the course of this study. 


\section{Conflicts of Interest}

The author declares no conflicts of interest regarding the publication of this paper.

\section{References}

[1] Arbach-Lucioni, K., Martinez-García, M. and Andrés-Pueyo, A. (2012) Risk Factors for Violent Behavior in Prison Inmates: A Cross-Cultural Contribution. Criminal Justice and Behavior, 39, 1219-1239.

[2] DeLisi, M., Caudill, J.W., Trulson, C.R., Marquart, J.W., Vaughn, M.G. and Beaver, K.M. (2010) Angry Inmates Are Violent Inmates: A Poisson Regression Approach to Youthful Offenders. Journal of Forensic Psychology Practice, 10, 419-439. https://doi.org/10.1080/15228932.2010.489861

[3] Slaby, R.G. and Guerra, N.G. (1988) Cognitive Mediators of Aggression in Adolescent Offenders: I. Assessment. Developmental Psychology, 24, 580-588. https://doi.org/10.1037/0012-1649.24.4.580

[4] Wolfgang, M.E. and Ferracuti, F. (1967) The Subculture of Violence: Towards an Integrated Theory in Criminology. Tavistock Publications, London.

[5] Arsenio, W.F. and Gold, J. (2006) The Effects of Social Injustice and Inequality on Children's Moral Judgments and Behavior: Towards a Theoretical Model. Cognitive Development, 21, 388-400. https://doi.org/10.1016/j.cogdev.2006.06.005

[6] Cornell, D.G., Warren, J., Hawk, G., Stafford, E., Oram, G. and Pine, D. (1996) Psychopathy in Instrumental and Reactive Violent Offenders. Journal of Consulting and Clinical Psychology, 64, 783-790. https://doi.org/10.1037/0022-006x.64.4.783

[7] Raine, A., Moffitt, T.E., Caspi, A., Loeber, R., Stouthamer-Loeber, M. and Lynam, D. (2005) Neurocognitive Impairments in Boys on the Life-Course Persistent Antisocial Path. Journal of Abnormal Psychology, 114, 38-49. https://doi.org/10.1037/0021-843x.114.1.38

[8] Fabian, J.M. (2010) Neuropsychological and Neurological Correlates in Violent and Homicidal Offenders: A Legal and Neuroscience Perspective. Aggression and Violent Behavior, 15, 209-223. https://doi.org/10.1016/j.avb.2009.12.004

[9] Smithmyer, C.M., Hubbard, J.A. and Simons, R.F. (2000) Proactive and Reactive Aggression in Delinquent Adolescents: Relations to Aggression Outcome Expectancies. Journal of Clinical Child Psychology, 29, 86-93. https://doi.org/10.1207/S15374424jccp2901_9

[10] Muris, P., Meesters, C., Morren, M. and Moorman, L. (2004) Anger and Hostility in Adolescents: Relationships with Self-Reported Attachment Style and Perceived Parental Rearing Styles. Journal of Psychosomatic Research, 57, 257-264. https://doi.org/10.1016/S0022-3999(03)00616-0

[11] Muniz, C.N., Fox, B., Miley, L.N., Delisi, M., Cogarran, G.P. and Birnbaum, A. (2019) The Effects of Adverse Childhood Experiences on Internalizing versus Externalizing Outcomes. Criminal Justice and Behavior, 46, 568-589. https://doi.org/10.1177/0093854819826213

[12] Ellis, L., Farrington, D. and Hoskin, A. (2019) Handbook of Crime Correlates. 2nd Edition, Academic Press, Cambridge.

[13] Wheeler, S. (1961) Socialization in Correctional Communities. American Sociological Review, 26, 697-712. https://doi.org/10.2307/2090199

[14] Walters, G.D. (2008) Criminal Predatory Behavior in the Federal Bureau of Prisons. 
In: DeLisi, M. and Conis, P.J., Eds., Violent Offenders: Theory, Research, Public Policy, and Practice, Jones and Bartlett, Boston, 191-204.

[15] Walters, G.D. (2003) Changes in Criminal Thinking and Identity in Novice and Experienced Inmates: Prisonization Revisited. Criminal Justice and Behavior, 30, 399-421. https://doi.org/10.1177/0093854803253137

[16] Chapman, J.F., Desai, R.A., Falzer, P.R. and Borum, R. (2006) Violence Risk and Race in a Sample of Youth in Juvenile Detention: The Potential to Reduce Disproportionate Minority Confinement. Youth Violence and Juvenile Justice, 4, 170-184. https://doi.org/10.1177/1541204006286316

[17] Duenkel, F. (2014) Juvenile Justice Systems in Europe-Reform Developments between Justice, Welfare and 'New Punitiveness'. Kriminologijos Studijos, 1, 31-76.

[18] NAP (2014) Raport Anual de Activitate 2014. Ministry of Justice-National Administration of Penitentiary's Office, Bucharest.

[19] Baias, C.-V. and Beckwith-Finnegan, J.. (2021) The Epidemiology of Self-Harm in the Romanian Juvenile Prison System: A Two-Year Cohort Study. Open Journal of Epidemiology, 11, 371-389. https://doi.org/10.4236/ojepi.2021.114031

[20] Bebbington, P., Jakobowitz, S., McKenzie, N., et al. (2017) Assessing Needs for Psychiatric Treatment in Prisoners: 1. Prevalence of Disorder. Social Psychiatry and Psychiatric Epidemiology, 52, 221-229. https://doi.org/10.1007/s00127-016-1311-7

[21] Derogatis, L.R., Lipman, R.S. and Covi, L. (1973) SCL-90: An Outpatient Psychiatric Rating Scale-Preliminary Report. Psychopharmacology Bulletin, 9, 13-28.

[22] Bowler, N., Phillips, C. and Rees, P. (2018) The Association between Imported Factors and Prisoners Mental Health: Implications for Adaptation and Intervention. International Journal of Law and Psychiatry, 57, 61-66. https://doi.org/10.1016/j.ijlp.2018.01.001

[23] Hosmer, D., Lemeshow, S. and May, S. (2009) Applied Survival Analysis. 2nd Edition, Wiley-Interscience, Hoboken.

[24] Amorim, L.D. and Cai, J. (2015) Modelling Recurrent Events: A Tutorial for Analysis in Epidemiology. International Journal of Epidemiology, 44, 324-333.

https://doi.org/10.1093/ije/dyu222

[25] Lawless, J. and Nadeau, C. (1995) Some Simple Robust Methods for the Analysis of Recurrent Events. Technometrics, 37, 158-168.

[26] Rhule-Louie, D.M. and McMahon, R.J. (2007) Problem Behaviour and Romantic Relationships: Assortative Mating, Behaviour Contagion and Desistance. Clinical Child and Family Psychology Review, 10, 53-100.

https://doi.org/10.1007/s10567-006-0016-y

[27] Yexley, M., Borowsky, I. and Ireland, M. (2002) Correlation between Different Experiences of Intrafamilial Physical Violence and Violent Adolescent Behavior. Journal of Interpersonal Violence, 17, 707-720. https://doi.org/10.1177/0886260502017007001

[28] Rivlin, A., Hawton, K., Marzano, L. and Fazel, S. (2013) Psychosocial Characteristics and Social Networks of Suicidal Prisoners: Towards a Model of Suicidal Behaviour in Detention. PLoS ONE, 8, e68944. https://doi.org/10.1371/journal.pone.0068944

[29] Baumer, E.P., O’Donnell, I. and Hughes, N. (2009) The Porous Prison: A Note on the Rehabilitative Potential of Visits Home. The Prison Journal, 89, 119-126. https://doi.org/10.1177/0032885508330430

[30] Morgan, A.B. and Lilienfeld, S.O. (2000) A Meta-Analytic Review of the Relation between Antisocial Behaviour and Neuropsychological Measures of Executive 
Function. Clinical Psychology Review, 20, 113-136.

https://doi.org/10.1016/s0272-7358(98)00096-8

[31] Frick, P.J. and White, S.F. (2008) Research Review: The Importance of Callous-Unemotional Traits for Developmental Models of Aggressive and Antisocial Behaviour. Journal of Child Psychology and Psychiatry, 49, 359-375.

https://doi.org/10.1111/j.1469-7610.2007.01862.x

[32] Gottfredson, M.R. and Hirschi, T. (1990) A General Theory of Crime. Stanford University Press, Redwood City. 